\title{
METHOD DEVELOPMENT AND VALIDATION FOR SIMULTANEOUS ESTIMATION OF CLOTRIMAZOLE, MICONAZOLE NITRATE, AND TINIDAZOLE BY REVERSED-PHASE HIGH-PERFORMANCE LIQUID CHROMATOGRAPHY METHOD IN TABLETS
}

\author{
DEEPIKA SHARMA, KOMAL GUPTA, POOJA CHAWLA* \\ Department of Pharmaceutical Analysis, ISF College of Pharmacy, Moga, Punjab, India. Email: pvchawla@gmail.com \\ Received: 08 June 2019, Revised and Accepted: 12 July 2019
}

\section{ABSTRACT}

Objective: The aim of the study is to develop and validate a high-performance liquid chromatographic method for the simultaneous determination of clotrimazole, miconazole nitrate, and tinidazole tablet dosage forms.

Materials and Methods: $A$ Waters $\mathrm{C}_{18}$ column $(50 \mathrm{~mm} \times 4.6 \mathrm{~mm}, 5 \mu \mathrm{m})$ with mobile phase consisting of acetonitrile, methanol, and water 55:25:20 (v/v) (pH 2.5 adjusting with $0.5 \%$ orthophosphoric acid) was used. The flow rate was $1.0 \mathrm{ml} / \mathrm{min}$, and effluents were monitored at $210 \mathrm{~nm}$.

Results: The retention time of miconazole nitrate, tinidazole, and clotrimazole tablets was found to be $2.9 \mathrm{~min}, 3.5 \mathrm{~min}$, and $4.7 \mathrm{~min}$, respectively. The method was validated according to the ICH guidelines for specificity, limit of detection, limit of quantification, precision, accuracy, linearity, ruggedness, and robustness.

Conclusion: The method shows good reproducibility and recovery with \% relative standard deviation $<2$. Hence, the proposed method was found to be simple, specific, precise, accurate, and linear. Hence, it can be applied for routine analysis of clotrimazole, miconazole nitrate, and tinidazole in pharmaceutical combined dosage forms.

Keywords: Reversed-phase high-performance liquid chromatography, Clotrimazole, Miconazole nitrate, Tinidazole, ICH guidelines.

(c) 2019 The Authors. Published by Innovare Academic Sciences Pvt Ltd. This is an open access article under the CC BY license (http://creativecommons. org/licenses/by/4. 0/) DOI: http://dx.doi.org/10.22159/ajpcr.2019.v12i9.34505

\section{INTRODUCTION}

Nowadays, combined dosage forms are mostly preferred when compared to single dosage forms. Clotrimazole, miconazole nitrate, and tinidazole are available in combined pharmaceutical dosage form. The brand name is Defung vaginal tablet containing $20 \mathrm{mg}$ of clotrimazole, $100 \mathrm{mg}$ of miconazole nitrate, and $500 \mathrm{mg}$ of tinidazole for the treatment of various vaginal infections [1]. Literature survey reveals that various analytical methods have been reported for single dosage forms. The present paper aims to report a simple, accurate, precise, and reversed-phase high-performance liquid chromatography (RP-HPLC) method for simultaneous estimation of clotrimazole, miconazole nitrate, and tinidazole in combined dosage forms.

\section{Drug profile of clotrimazole}

Its IUPAC name is 1-[(2-chlorophenyl)-diphenylmethyl]imidazole (Fig. 1). The molecular formula is $\mathrm{C}_{22} \mathrm{H}_{17} \mathrm{ClN}_{2}$. It is an antifungal drug used in the treat of fungal infections, and it is white-to-pale yellow crystalline powder which is soluble in methanol and acetonitrile [3-5].

\section{Drug profile of miconazole nitrate}

It is a 1-[2-(2,4-dichlorophenyl)-2-[(2,4-dichlorophenyl)methoxy] ethyl]imidazole nitric acid (Fig. 2), and it has broad-spectrum antifungal activity against various Candida species including Candida albicans, Candida tropicalis, Candida glabrata, and Candida krusei. It is white to off-white powder which is soluble in methanol and acetonitrile and insoluble in water $[7,8]$.

\section{Drug profile of tinidazole}

It is 1-[2-(ethanesulfonyl)ethyl]-2-methyl-5-nitroimidazole (Fig. 3), its molecular formula is $\mathrm{C}_{8} \mathrm{H}_{13} \mathrm{~N}_{3} \mathrm{O}_{4} \mathrm{~S}$ and this is an antiprotozoal, antibacterial agent. Tinidazole inhibits protozoal organisms like
Trichomonas vaginalis, Tritrichomonas foetus, and Entamoeba histolytica. It is white or pale yellow crystalline powder, and it is soluble in methanol and acetonitrile [10-12].

\section{MATERIALS AND METHODS}

Optimized chromatographic conditions

Suitable HPLC equipped with ultraviolet (UV)-visible detector was used. HPLC (Waters, 2695 separation module) Software (Empower, version 2.0).

- Column: waters C18, $50 \mathrm{~mm} \times 4.6$

- Wavelength: $210 \mathrm{~nm}$

- Injection volume: $20 \mu \mathrm{l}$

- Column temperature: Ambient

- Flow rate: $1.0 \mathrm{ml} / \mathrm{min}$.

Retention time of clotrimazole, miconazole nitrate, and tinidazole are $4.7,2.9$, and $3.5 \mathrm{~min}$, respectively.

\section{Chemicals and reagents}

Clotrimazole, miconazole nitrate, and tinidazole were received as gift sample from ISF Analytical Laboratories, Moga, Punjab, India. The marketed formulation for the combination named as Defung Vaginal Tablets (Indica Laboratories Pvt. Ltd.,) containing $20 \mathrm{mg}$ of clotrimazole, $100 \mathrm{mg}$ of miconazole nitrate, and $500 \mathrm{mg}$ of tinidazole was purchased from local market. The solvents which were used during the method development and validation were HPLC grade methanol (S.D Fine Chemicals Ltd, Mumbai, India) and HPLC grade acetonitrile and water for HPLC (Finar Chemicals Ltd., Mumbai, India). The analytical reagent grade orthophosphoric acid (OPA) (Ranbaxy Laboratories Ltd) was used to adjust the $\mathrm{pH}$ of mobile phase which is filtered through a nylon $0.45 \mu \mathrm{m}$ membrane filter paper (Gelman laboratories Mumbai, India). 


\section{RP-HPLC method}

HPLC system of waters (Milford, USA) composed of 515 HPLC pump as a solvent delivery system equipped with Rheodyne injection valve with a $50 \mu$ loop. The chromatographic separation was performed with a Waters, 2695 separation module HPLC instrument equipped with UV-visible detector and Empower software, version 2.0. The Waters $\times$ Bridge Stainless steel $\mathrm{C}_{18}$ column $(250 \mathrm{~mm} \times 4.6 \mathrm{~mm}, 5 \mu \mathrm{m})$ packed with octadecylsilane chemically bounded porous silica particles was used as stationary phase for analysis. BL-220H analytical balance (Shimadzu Corporation, Japan), an ultrasonic cleaner (Frontline FS 4, Mumbai, India), and Digital pH meter (LI 612 pH analyzer, Elico Ltd., Ahmedabad) were used in the study.

\section{Chromatographic conditions}

The optimal composition of the mobile phase was determined to be acetonitrile:methanol:water, $\mathrm{pH}$ adjusted to 2.5 with OPA (40:30:30v/v). The mobile phase was filtered through nylon $0.22 \mu \mathrm{m}$ membrane filters and was degassed to remove the air before use (30 min). Stock solution was prepared by dissolving clotrimazole, miconazole nitrate, and tinidazole $(25 \mathrm{mg}$ of clotrimazole and miconazole nitrate and $50 \mathrm{mg}$ of tinidazole) that were weighed accurately and separately transferred into $25 \mathrm{ml}$ volumetric flasks. All the drugs were dissolved in $25 \mathrm{ml}$ of mobile phase to prepare standard stock solutions followed by sonication. After the immediate dissolution, sonicate the solution and make up the volume up to the mark with mobile phase. These standard stock solutions were observed to contain $1 \mathrm{mg} / \mathrm{ml}$ of clotrimazole and miconazole nitrate and $2 \mathrm{mg} / \mathrm{ml}$ of tinidazole. Appropriate volume from this solution was further diluted to get appropriate concentration levels according to the requirement. From the above stock solutions, dilutions were made in the concentration range of 4.8, 6.4, 8, 9.6, and $11.2 \mu \mathrm{g} / \mathrm{ml}$ for clotrimazole; $32,36,40,44$, and $48 \mu \mathrm{g} / \mathrm{ml}$ for miconazole nitrate; and $160,180,200,220$, and $240 \mu \mathrm{g} / \mathrm{ml}$ for tinidazole. A volume of $50 \mu \mathrm{l}$ of each sample was injected into column.

\section{Preparation of mobile phase}

Mobile phase was prepared by mixing acetonitrile (HPLC grade), methanol (HPLC grade), and water (HPLC grade) pH 2.5 (55:25:20 v/v). Mixture was shaken vigorously and sonicated for 30 min before use. The $\mathrm{pH}$ was adjusted by OPA using $\mathrm{pH}$ meter (Eutech Instruments, Singapore). The prepared mobile phase was passed through $0.22 \mu \mathrm{m}$ membrane filter (Millipore, USA).

\section{Preparation of stock solutions}

Stock solutions and sample solutions of clotrimazole, miconazole nitrate, and tinidazole and its ternary mixture were prepared by adding accurately weighed $25 \mathrm{mg}$ of clotrimazole and miconazole nitrate and $50 \mathrm{mg}$ of tinidazole separately in $25 \mathrm{ml}$ volumetric flask containing $15 \mathrm{ml}$ of mobile phase. The flasks were then sonicated for $10 \mathrm{~min}$, and the volume was made up to the mark using mobile phase. These standard stock solutions were containing $1000 \mu \mathrm{g} / \mathrm{ml}$ of clotrimazole and miconazole nitrate and $2000 \mu \mathrm{g} / \mathrm{ml}$ of tinidazole. Stock solutions were used to prepare desired concentration range as per sample calibration range.

\section{Preparation of sample solutions}

Twenty tablets were weighed and emptied. The equivalent weight was calculated, and according to average weight, required drug was taken in volumetric flask to obtain $20 \mathrm{mg}$ of clotrimazole, $100 \mathrm{mg}$ of miconazole nitrate, and $500 \mathrm{mg}$ of tinidazole in single dilution, i.e., according to the label claim of the formulation. The dilutions were first sonicated and then filtered through 0.22 micron filter paper.

\section{Preparation of calibration curve}

The test concentrations for clotrimazole, miconazole nitrate, and tinidazole in HPLC method development were found to be $8 \mu \mathrm{g} / \mathrm{ml}, 40 \mu \mathrm{g} / \mathrm{ml}$, and $200 \mu \mathrm{g} / \mathrm{ml}$, respectively. The calibration curve was prepared by injecting the concentrations of $6.4-9.6 \mu \mathrm{g} / \mathrm{ml}$ of clotrimazole, $32-48 \mu \mathrm{g} / \mathrm{ml}$ of miconazole nitrate, and $160-240 \mu \mathrm{g} / \mathrm{ml}$ of tinidazole in ternary mixture solution manually in triplicate to the HPLC

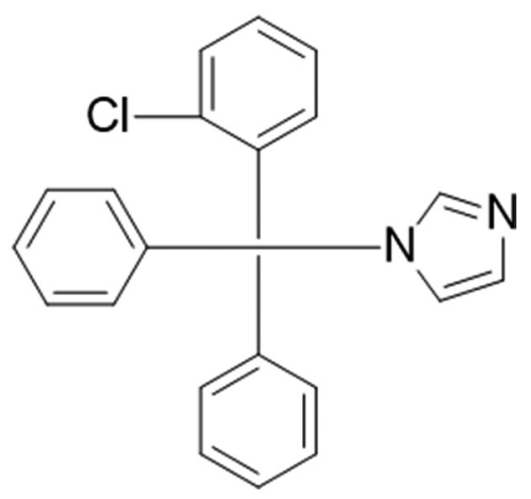

Fig. 1: Structure of clotrimazole [2]<smiles>O=[N+]([O-])O</smiles>

Fig. 2: Structure of miconazole nitrate [6]<smiles>CCOS(=O)(=O)CCn1c([N+](=O)[O-])cnc1C</smiles>

Fig. 3: Structure of tinidazole [9]

system at detection wavelength of $210 \mathrm{~nm}$. Mean of $\mathrm{n}=5$ determinations was plotted as the standard curve. The calibration curve was tested by validating it with interday and intraday measurements. Linearity, accuracy, and precision were determined for both interday and intraday measurement.

\section{Method validation}

Linearity

The methods were validated according to the International Conference on Harmonization Q2B guidelines (2005) for validation of analytical procedures to determine the linearity, sensitivity, precision, and accuracy for each analyte. Calibration curves were generated with appropriate volumes of working standard solutions for HPLC.

For HPLC assay method validation, the test concentrations were found to be $8 \mu \mathrm{g} / \mathrm{ml}$ of clotrimazole, $40 \mu \mathrm{g} / \mathrm{ml}$ of miconazole nitrate, and $200 \mu \mathrm{g} / \mathrm{ml}$ of tinidazole. Linearity of the proposed method was carried out by the preparation of $80 \%, 90 \%, 100 \%, 110 \%$, and $120 \%$ of clotrimazole, miconazole nitrate, and tinidazole and test concentration, i.e., $6.4,7.2,8,8.8$, and $9.6 \mu \mathrm{g} / \mathrm{ml}$ for clotrimazole; $32,36,40,44$, and $48 \mu \mathrm{g} / \mathrm{ml}$ for miconazole nitrate; and 160, 180, 200, 220, and $240 \mu \mathrm{g} / \mathrm{ml}$ for tinidazole. The linearity was evaluated by the least square regression method using data as shown in Table 1.

\section{Precision and accuracy}

Both precision and accuracy were determined with standard quality control samples (in addition to calibration standards) prepared in triplicates at different concentration levels covering the entire linearity range. Precision is the degree of repeatability of an analytical method 
under normal operational conditions. The precision of the assay was determined by repeatability (intraday) and intermediate precision (interday) and reported as percent relative standard deviation (\% RSD) for a statistically significant number of replicate measurements. The intermediate precision was studied by comparing the assays on three different days, and the results documented as standard deviation and $\%$ RSD [13].

Accuracy is the percent of analyte recovered by assay from a known added amount. For the measurement of accuracy, data from nine determinations over three concentration levels covering the specified range were determined. The samples containing $80 \%, 100 \%$, and $120 \%$ of test concentrations were spiked with $100 \%$ of standard solution in HPLC, and percentage recovery was calculated $[14,15]$ as shown in Table 2 .

Limit of detection (LOD) and limit of quantification (LOQ)

The LOD is defined as the lowest concentration of an analyte that an analytical process can reliably differentiate from background levels. The LOQ is defined as the lowest concentration of the standard curve that can be measured with acceptable accuracy, precision, and variability [15].

The LOD and LOQ were calculated as,

$\mathrm{LOD}=3.3 \sigma / \mathrm{S}$

$\mathrm{LOQ}=10 \sigma / \mathrm{S}$

Where $\sigma$ is the standard deviation of the lowest standard concentration and $\mathrm{S}$ is the slope of the standard curve as shown in Table 1.
Stability

The stability of clotrimazole, miconazole nitrate, and tinidazole in mobile phase was assessed by analyzing the sample concentrations at $1 \mathrm{~h}, 4 \mathrm{~h}, 9 \mathrm{~h}, 24 \mathrm{~h}, 48 \mathrm{~h}$, and $60 \mathrm{~h}$. The concentrations used in this study were $8 \mu \mathrm{g} / \mathrm{ml}$ for clotrimazole, $40 \mu \mathrm{g} / \mathrm{ml}$ for miconazole nitrate, and $200 \mu \mathrm{g} / \mathrm{ml}$ for tinidazole prepared from stock solution of pure form and powdered capsule sample, respectively. Six replicate samples for each concentration were assayed at each time point. The stability was tested over a period of 3 days at room temperature.

\section{Robustness}

The effect of intentional variation in analytical conditions such as detection wavelength, mobile phase flow rate, and mobile phase composition on the retention time, and peak area was investigated one by one in Table 1.

\section{Analysis of marketed tablets formulation by HPLC}

Accurately weighed powder sample equivalent to $20 \mathrm{mg}$ of clotrimazole, $100 \mathrm{mg}$ of miconazole nitrate, and $500 \mathrm{mg}$ of tinidazole was dissolved in a $50 \mathrm{ml}$ volumetric flask containing mobile phase. The solution was kept for sonication for 20 min, filtered through Whatman Filter Paper No. 41. Aliquot of this solution was diluted to produce the concentration of $8 \mu \mathrm{g} / \mathrm{ml}$ for clotrimazole, $40 \mu \mathrm{g} / \mathrm{ml}$ for miconazole nitrate, and $200 \mu \mathrm{g} /$ $\mathrm{ml}$ for tinidazole $(\mathrm{n}=6)$.

\section{RESULTS}

RP-HPLC spectrophotometric methods were developed for clotrimazole, miconazole nitrate, and tinidazole which can be conveniently employed for routine analysis in pharmaceutical dosage forms and will eliminate unnecessary tedious sample preparations. The chromatographic conditions were optimized to provide a good performance of the

Table 1: Summary of the HPLC method validation

\begin{tabular}{|c|c|c|c|c|}
\hline S. No & Validation parameter & Clotrimazole & Miconazole nitrate & Tinidazole \\
\hline 1. & Absorption maxima, $\chi_{\text {max }}(\mathrm{nm})$ & 210 & 210 & 210 \\
\hline 2. & Linearity range $(\mu \mathrm{g} / \mathrm{ml})$ & $6.4-9.6$ & $32-48$ & $160 v 240$ \\
\hline 3. & Coefficient of determination $\left(\mathrm{R}^{2}\right)$ & 0.998 & 0.997 & 0.999 \\
\hline 4. & Regression equation (y) & $Y=52494 x+26711$ & $Y=44103 x-79083$ & $Y=14390 x-27218$ \\
\hline 5. & Slope (b) & 52494 & 44103 & 14390 \\
\hline 6. & Intercept (a) & 26711 & 79083 & 27218 \\
\hline 7. & Limit of detection $(\mu \mathrm{g} / \mathrm{ml})$ & 0.159 & 2.726 & 4.219 \\
\hline \multirow[t]{2}{*}{9.} & Precision (\% RSD) & Intraday $=0.524$ & Intraday $=0.410$ & Intraday=1.26 \\
\hline & & Interday $=0.540$ & Interday=0.693 & Interday $=1.28$ \\
\hline \multirow[t]{2}{*}{10.} & Solution stability $>12 \mathrm{~h}$ & Stable up to $24 \mathrm{~h}$ & Stable up to $24 \mathrm{~h}$ & Stable up to $24 \mathrm{~h}$ \\
\hline & & $\% \mathrm{RSD}=0.645$ & $\% \mathrm{RSD}=0.65$ & $\% \mathrm{RSD}=0.756$ \\
\hline \multirow[t]{6}{*}{11.} & Robustness (\% RSD) & complies & complies & Complies \\
\hline & Flow plus & 0.460 & 0.640 & 0.733 \\
\hline & Flow minus & 0.315 & 0.454 & 0.809 \\
\hline & Organic plus & 0.665 & 0.598 & 0.527 \\
\hline & Wavelength plus & 0.201 & 0.448 & 0.393 \\
\hline & Wavelength minus & 0.315 & 0.566 & 0.482 \\
\hline
\end{tabular}

RSD: Relative standard deviation, HPLC: High-performance liquid chromatography

Table 2: Recovery study by HPLC methods

\begin{tabular}{|c|c|c|c|c|}
\hline Method & Drug & Amount present $(\mu \mathrm{g} / \mathrm{ml})$ & Amount spiked $(\mu \mathrm{g} / \mathrm{ml})$ & Percent recovery* \\
\hline \multirow[t]{8}{*}{ HPLC method } & Clotrimazole & 6.4 & 8 & 100.31 \\
\hline & & 8 & 8 & 96.59 \\
\hline & & 9.6 & 8 & 102.51 \\
\hline & Miconazole nitrate & 32 & 40 & 102.82 \\
\hline & & 40 & 40 & 99.98 \\
\hline & & 48 & 40 & 99.93 \\
\hline & Tinidazole & 160 & 200 & 100.31 \\
\hline & & 240 & 200 & 99.72 \\
\hline
\end{tabular}

*Average of six determinations, HPLC: High-performance liquid chromatography 


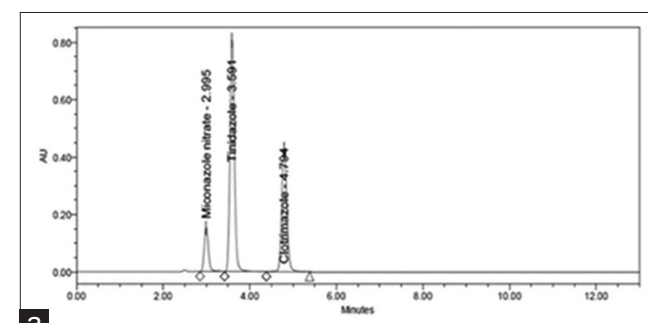

a
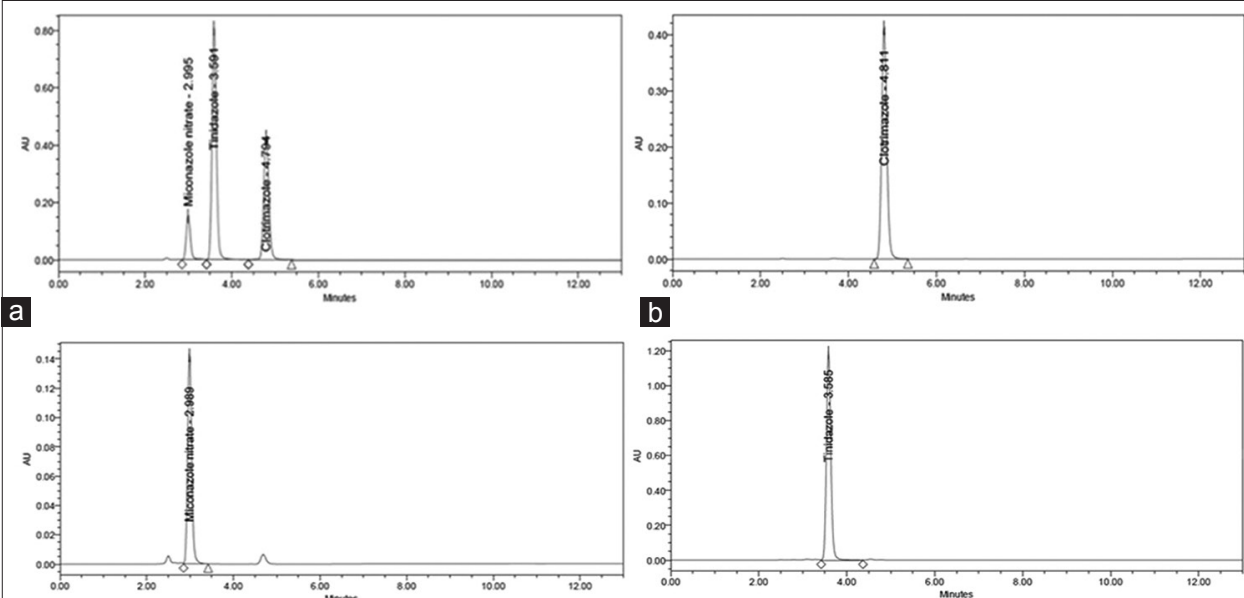

b

c

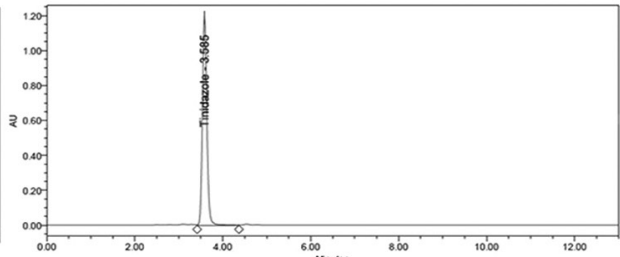

d

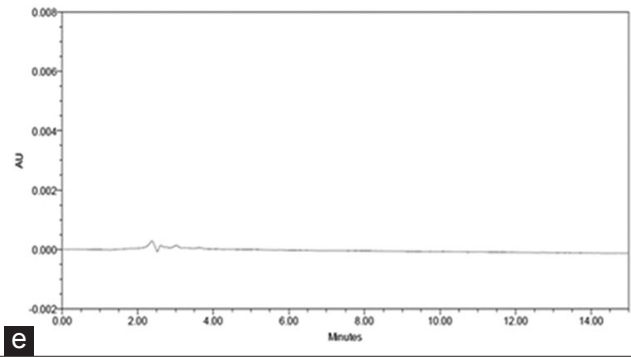

Fig. 4: (a) Chromatograms of clotrimazole, miconazole nitrate, and tinidazole. (b) Chromatogram of clotrimazole at test concentration. (c) Chromatogram of miconazole nitrate at test concentration. (d) Chromatogram of tinidazole at test concentration, (e) Chromatogram of blank

Table 3: System suitability studies of clotrimazole, miconazole nitrate, and tinidazole in optimized RP-HPLC compared with USP limits

\begin{tabular}{|c|c|c|c|c|c|}
\hline S. No & Parameters & USP limit & Clotrimazole & Miconazole nitrate & Tinidazole \\
\hline 1. & Conc. $(\%)$ & - & $100 \%$ & $100 \%$ & $100 \%$ \\
\hline 2. & Retention time & - & 4.834 & 3.003 & 3.558 \\
\hline 3. & Average peak area of 6 injection & - & 3517422 & 1051242 & 5759661 \\
\hline 4. & $\%$ RSD of peak area of 6 injections & $\leq 2.0$ & 0.425 & 0.569 & 0.676 \\
\hline 5. & Peak asymmetry (at $10 \%$ peak height) & $\leq 1.5$ & 1.69 & 1.73 & 1.52 \\
\hline 6. & Mean number of theoretical plate & $\geq 2000$ & 2218 & 2289 & 2434 \\
\hline 7. & Final retention time & - & 4.794 & 2.995 & 3.591 \\
\hline
\end{tabular}

RSD: Relative standard deviation, RP-HPLC: Reversed-phase high-performance liquid chromatography

assay. The retention time of clotrimazole, miconazole nitrate, and tinidazole in tablets formulation was found to be $4.7 \mathrm{~min}, 2.9 \mathrm{~min}$, and 3.5 min, respectively. The chromatograms have been shown in Fig. 4a. A five-point calibration curve was constructed with working standards and was found linear for each of the analyte over their calibration ranges. The slopes were calculated using the plot of drug concentration versus area of the chromatogram. The developed HPLC method was accurate, precise, reproducible, and very sensitive as shown in below Fig 4 .

All the method validation parameters are well within the limits as specified in the ICH Q2B guidelines as shown in Tables 1 and 2 lists, the percent recovery (content uniformity) of all the drugs in the commercial formulations by HPLC methods. Moreover, the \% RSD (less variation) shows good precision of developed method [16]. The calculated LOQ and LOD concentrations confirmed that the methods were sufficiently sensitive. Various system suitability parameters are shown in Table 3. The methods were suitably employed for assaying all the drugs in commercial marketed formulation (Table 4)

\section{DISCUSSION}

All the method validation parameters were well within the limits as specified in the ICH Q2B guidelines. Moreover, the \% RSD (less variation) showed good precision of developed method. The calculated LOQ and
Table 4: Assay of marketed formulation Defung vaginal tablets by HPLC methods

\begin{tabular}{llll}
\hline Drug & Label claim (mg) & Amount found (mg) & \% assay \\
\hline $\begin{array}{l}\text { Clotrimazole } \\
\text { Miconazole }\end{array}$ & 100 & 21.443 & 99.83 \\
$\begin{array}{l}\text { nitrate } \\
\text { Tinidazole }\end{array}$ & 500 & 100.501 & 100.05 \\
\hline
\end{tabular}

HPLC: High-performance liquid chromatography

LOD concentrations confirmed that the methods were sufficiently sensitive. Various system suitability parameters are shown which show that the method is simple, accurate rapid, and precise. The method was suitably employed for assaying all the drugs in commercial marketed formulation. Hence, the developed can be used for further studies, and it helps researches to determine the drug content in formulation.

\section{CONCLUSION}

Simple, rapid, accurate, and precise RP-HPLC methods have been developed and validated for the routine analysis of clotrimazole, miconazole nitrate, and tinidazole in active pharmaceutical ingredient and tablets dosage forms. The method is suitable for the simultaneous 
determination of clotrimazole, miconazole nitrate, and tinidazole in multicomponent formulations without the interference of each other. The developed method is suggested for routine and quality control analysis of the investigated drugs in ternary component pharmaceutical preparations. The amount found from the proposed methods is in good conformity with the label claim of the formulation. Furthermore, the value of standard deviation and coefficient of variation calculated are acceptably low, indicating the suitability of the proposed methods for the routine estimation of tablets dosage forms.

\section{AUTHORS' CONTRIBUTION}

Deepika Sharma: Carried out the research work. Komal Gupta: Assisted in drafting the manuscript. Dr. Pooja Chawla: Research Supervisor.

\section{ACKNOWLEDGMENTS}

The authors express their thanks to the Chairman of the ISF College of Pharmacy, Moga, for providing excellent research facilities.

\section{CONFLICTS OF INTERESTS}

The authors confirm that this article content has no conflict of interest.

\section{REFERENCES}

1. Defung Vaginal Tablets: Uses, Price, Side Effects, Composition, Substitutes, Precautions and Advice-Indica Laboratories Pvt Ltd Strip of 8 tablets. Available from: https://www.1mg.com/drugs/defung20mg-100mg-500mg-vaginal-tablet-293771. [Last accessed on 2019 May 10].

2. Crowley PD, Gallagher HC. Clotrimazole as a pharmaceutical: Past, present and future. J Appl Microbiol 2014;117:611-7.

3. Seethalakshmi N, Chenthilnathan A, Rama K. RP-HPLC method development and validation for simultaneous estimation of metronidazole, clindamycin phosphate and clotrimazole in combined pharmaceutical dosage forms. Int Res J Pharm Appl Sci 2014;4:67-77.

4. Joshi S, Majmudar F. Analytical method development and validation for simultaneous estimation of clotrimazole and tinidazole by RP-HPLC. Int J Pharm Res Sch 2015;4:135-40.

5. Dhake AS, Shinkar DM, Shayle S, Patil SB, Setty CM. Development and evaluation of mucoadhesive tablets of clotrimazole and its $\beta$-cyclodextrin complex for the treatment of candidiasis. Int J Pharm Pharm Sci 2011;3:159-64.

6. Prava VR, Seru G. RP-HPLC method development and validation for the simultaneous determination of clindamycin and miconazole in pharmaceutical dosage forms. Pharm Methods 2014;5:56.

7. Sahoo DR, Jain S. A rapid and validated RP-HPLC method for the simultaneous quantification of benzoic acid, metronidazole and miconazole nitrate in vaginal formulations. J Chromatogr Sci 2016;54:1613-8

8. Barasch A, Griffin AV. Miconazole revisited: New evidence of antifungal efficacy from laboratory and clinical trials. Future Microbial 2008:3:265-9.

9. Madhuri K, Senthil KM, Kalyani L. A review on tinidazole. Int J Pharm Chem Bio Sci 2011;1:38-42.

10. Rani NU, Rao JV. Estimation of tinidazole in tablets by RP-HPLC method. Int J Chem Sci 2010;8:2325-30.

11. Dharuman J, Vasudevan M, Somasekaran KN, Dhandapania B, Ghodea PS, Thiagarajana M. RP-HPLC method development and validation for the simultaneous estimation of ofloxacin and tinidazole in tablets. Int J PharmTech Res 2009;1:121-4.

12. Kumar DV, Swetha P, Prasad GS, Kumar AA. Assay method development and validation for simultaneous quantitative estimation of diloxanide furoate and ornidazole in tablets by RP-HPLC. Int J Pharm Pharm Sci 2015;7:357-62.

13. Swartz ME, Krull IS. Analytical method development and validation. J Am Chem Soc 1997;22:104-19.

14. Ahuja S, Rasmussen H. HPLC Method Development for Pharmaceuticals. $1^{\text {st }}$ ed. Boca Raton, FL: Elsevier; 1997. p. 145-86.

15. Vidushi Y, Meenakshi B. A review on HPLC method development and validation. Res J Life Sci Bioinform Pharm Chem Sci 2017;2:178.

16. International Conference on Harmonization of Technical Requirements for Registration of Pharmaceuticals for Human use ICH Harmonized Tripartite Guideline on Validation of Analytical Procedures: Text and Methodology Q2 (R1) 